\title{
Canine angiostrongylosis in Italy: occurrence of Angiostrongylus vasorum in dogs with compatible clinical pictures
}

\author{
Donato Traversa - Angela Di Cesare $\cdot$ Silvana Meloni • \\ Antonio Frangipane di Regalbono • Piermarino Milillo • \\ Fabrizio Pampurini • Luigi Venco
}

Received: 20 January 2013 / Accepted: 26 March 2013 /Published online: 18 April 2013

(C) The Author(s) 2013. This article is published with open access at Springerlink.com

\begin{abstract}
This study evaluated the perception of veterinarians in including the emerging metastrongyloid Angiostrongylus vasorum in the differential diagnosis for dogs referred with appropriate signs. Veterinarians at teaching hospitals, private practices or kennels collected faecal samples from 606 symptomatic dogs in six different areas of Italy. The samples were examined with the Baermann technique. Fourteen dogs scored positive for A. vasorum, all showing different clinical pictures, with the most common reason for inclusion in the study being a combination of respiratory signs along with general signs. The most reported sign was cough, followed by aspecific distresses. Other respiratory signs were dyspnoea, tachypnoea and breathing sounds, while bleeding diathesis occurred in one dog. Gastrointestinal disorders were diarrhoea and vomitus, while no neurological signs were detected. Four key cases are herein described, with a special focus on their clinical description, findings at the collateral diagnostic imaging and
\end{abstract}

D. Traversa $(\bowtie) \cdot$ A. Di Cesare $\cdot$ S. Meloni $\cdot$ P. Milillo Dipartimento di Scienze Biomediche Comparate,

Università degli Studi di Teramo, Piazza Aldo Moro 45, 64100 Teramo, Italy

e-mail: dtraversa@unite.it

S. Meloni $\cdot$ L. Venco

Ospedale Veterinario "Città di Pavia", Viale Cremona 179,

27100 Pavia, Italy

A. Frangipane di Regalbono

Dipartimento di Medicina Animale, Produzioni e Salute,

Università degli Studi di Padova, Viale dell'Università 16,

35020 Legnaro (Pd), Italy

F. Pampurini

Bayer Sanità Animale, viale Certosa 130 ,

20156 Milan, Italy therapeutic options with moxidectin. This survey provides new data on distribution of $A$. vasorum in Europe and on the clinical impact of the disease. The results confirm that clinical angiostrongylosis overlaps a series of other conditions of dogs. Awareness among vet practitioners is discussed along with the importance of including A. vasorum on the list of differential diagnoses in canine clinical practice and of performing appropriate diagnostic methods.

\section{Introduction}

The metastrongyloid nematode Angiostrongylus vasorum affects the right chamber of the heart and pulmonary arteries of domestic dogs, wild canids and, occasionally, other animals (Levine 1980). In the past decade, clinical disease by $A$. vasorum in dogs has been described in both traditional endemic foci and previously free regions, and multiple reports showed an increasing number of infected animals over an expanding geographic range (Morgan et al. 2009; Helm et al. 2010; Morgan and Shaw 2010; Traversa et al. 2010a; Conboy 2011).

The interest on $A$. vasorum is growing, as demonstrated by recent studies which have reported new insights in biology, e.g. effect on environmental conditions on larval stages (Ferdushy and Hasan 2010a; Dias and Dos Santos Lima 2012), and diagnosis, e.g. via molecular methods (Al-Sabi et al. 2010; Jefferies et al. 2011), of canine angiostrongylosis.

On the other hand, the severity of clinical signs in infected dogs makes unlikely that $A$. vasorum has been neglected or unnoticed for prolonged periods in previously unrecognized endemic areas, especially in privately owned dogs. Cardiopulmonary distresses, bleeding disorders, haemorrhagic diathesis and neurological signs are typical 
clinical findings and they may occur either singly or in combination (Brennan 2008; Koch and Willesen 2009; Conboy 2011). Residing adult $A$. vasorum and inflammatory response to eggs and migrating larvae cause verminous pneumonia due to thrombotic endo-arteritis and vascular fibrosis (Prestwood et al. 1981; Koch and Willesen 2009; Gredal et al. 2011), while erratic larval migration and bleeding in the nervous system cause neurological signs (Perry et al. 1991; Garosi et al. 2005; Whitley et al. 2005; Wessmann et al. 2006; Denk et al. 2009). Nonspecific miscellaneous systemic and gastro-enteric signs may be other findings in infected dogs, either as a sole feature or along with the above more frequent features (Schelling et al. 1986; Bolt et al. 1994; Chapman et al. 2004; Koch and Willesen 2009; Helm et al. 2010).

Hence, canine angiostrongylosis has a widely varying clinical picture and the presentation of an infected patient is not straightforward and difficult to evaluate (Morgan et al. 2010).

A climatic envelope showed that Italy is among those areas offering suitable ecological and epidemiological conditions for the expansion of current dispersion of $A$. vasorum and the establishment of further new endemic foci (Morgan et al. 2009). At present, the infection in Italy is reported with increasing frequency in dogs, with highest values in central regions (Traversa et al. 2008a; Di Cesare et al. 2010, 2011, 2012). A similar pattern has been recently described in other countries where A. vasorum is considered emergent, e.g., Holland, Germany and Greece (Papazahariadou et al. 2007; van Doorn et al. 2009; Barutzki and Schaper 2009, 2011).

Nonetheless, information on infection rates and occurrence of $A$. vasorum in symptomatic dogs are lacking, especially because the disease is still neglected and underestimated in canine clinical practice. Thus, the aims of the present study were to evaluate the perception of veterinarians in Italy in including angiostrongylosis in differential diagnosis at their veterinary practices in primary care for symptomatic dogs and the occurrence of $A$. vasorum in animals presenting clinical signs compatible with the infection.

\section{Materials and methods}

\section{Study design}

The study was carried out in six regions in Northern (Veneto — site A, Lombardy—site B), Central (Marche - site C, Lazio - site D, Abruzzo - site E) and Southern (Apuliasite F) Italy. Veterinarians working in teaching veterinary hospitals and private practices, or visiting animals in kennels and shelters (see "Acknowledgments"), were asked to recruit at least 100 dogs in each area. Animals were selected when presenting a clinical picture considered compatible with canine angiostrongylosis even with a single sign suggestive of respiratory, cardiovascular, neurological or bleeding disorders appropriate for canine angiostrongylosis. At the moment of the visit time, veterinarians filled out a questionnaire for each animal including signalment, history and anamnesis, along with clinical signs. A faecal sample was collected from each recruited dog either immediately after a spontaneous defecation or by rectal inspection.

Faecal examination

All stool samples were examined by the Baermann technique as follows: about $5 \mathrm{~g}$ of faeces were placed in the centre of a double layer of cheesecloth sheet. A pouch containing the sample was formed by holding the four corners of the sheet together with a closing string. The pouch was placed in a funnel filled with water and kept at room temperature. After $24-48 \mathrm{~h}, 15 \mathrm{ml}$ of faecal fluid were drawn off from the bottom funnel into a tube and centrifuged at $600 \times g$ for $5 \mathrm{~min}$. The sediment was transferred onto a slide and microscopically examined. Larval nematodes retrieved were examined using existing descriptions and keys for metastrongyloid (McGarry and Morgan 2009; Traversa et al. 2010a).

\section{Results}

Dogs and clinical pictures

Overall, 606 symptomatic dogs were examined, i.e. 100 in sites A, D and F, 101 in sites B and E and 104 in site C. A plethora of different varying clinical pictures, (i.e. 210) consisting of 1 to 12 signs (Table 1), was considered compatible with angiostrongylosis by veterinarians collaborating in the six sites.

The most frequent signs considered pertinent with $A$. vasorum were cough, poor general conditions, weight loss and intolerance to exercise and, in particular, the sole presence of coughing without any other clinical evidence was thought enough to suspect angiostrongylosis in $98 \mathrm{dogs}$, from 1 in site A to 33 in site B (Table 1).

Other common complaints for visit and recruitment in the study for suspected angiostrongylosis by the veterinarians were non-specific cardiopulmonary signs, e.g. lethargy and exercise intolerance, or systemic in general, e.g. poor health conditions or weight loss.

Clinical evidences in dogs infected by A. vasorum

Of 606 symptomatic dogs included in the study, 14 (2.3\%) tested positive for the larvae of $A$. vasorum (Fig. 1): two in sites B (1.98\%) and D (2\%) and ten (9.9\%) in site E, while 
Table 1 Number of dogs with different clinical pictures (CP) consisting of a range $(\mathrm{R})$ of clinical signs present at the same time and considered compatible with angiostrongylosis by veterinarians in sites A (Veneto region), B (Lombardy region), C (Marche region), D
(Lazio region), E (Abruzzo region) and $\mathrm{F}$ (Apulia region). The three most frequent signs along with number of animals and percentages for each of them and along with dogs showing only cough (Co) or other cardiorespiratory signs (C-R) are also indicated

\begin{tabular}{|c|c|c|c|c|c|c|c|c|}
\hline \multirow{3}{*}{$\begin{array}{l}\text { Site } \\
\\
\text { A }\end{array}$} & \multirow{3}{*}{$\begin{array}{c}\text { Dogs } \\
100\end{array}$} & \multirow{3}{*}{$\begin{array}{l}\mathrm{CP} \\
\\
55\end{array}$} & \multirow{3}{*}{$\begin{array}{l}\mathrm{R} \\
1-10\end{array}$} & \multicolumn{5}{|l|}{ No. of dogs } \\
\hline & & & & \multicolumn{3}{|c|}{ Most frequent signs } & \multirow{2}{*}{$\frac{\mathrm{Co}}{1}$} & \multirow{2}{*}{$\frac{\mathrm{C}-\mathrm{R}}{0}$} \\
\hline & & & & $\begin{array}{l}\text { Diarrhoea } \\
52(52 \%)\end{array}$ & $\begin{array}{l}\text { Poor general conditions } \\
37(37 \%)\end{array}$ & $\begin{array}{l}\text { Weight loss } \\
30(30 \%)\end{array}$ & & \\
\hline B & 101 & 37 & $1-12$ & $\begin{array}{l}\text { Cough } \\
78(77.2 \%)\end{array}$ & $\begin{array}{l}\text { Poor general conditions } \\
41(40.6 \%)\end{array}$ & $\begin{array}{l}\text { Weight loss } \\
36(35.6 \%)\end{array}$ & 33 & 4 \\
\hline $\mathrm{C}$ & 104 & 24 & $1-6$ & $\begin{array}{l}\text { Cough } \\
74(71.2 \%)\end{array}$ & $\begin{array}{l}\text { Vomiting } \\
44(42.3 \%)\end{array}$ & $\begin{array}{l}\text { Low performance } \\
31(30.7 \%)\end{array}$ & 28 & 0 \\
\hline $\mathrm{D}$ & 100 & 42 & $1-8$ & $\begin{array}{l}\text { Cough } \\
90(90 \%)\end{array}$ & $\begin{array}{l}\text { Poor general conditions } \\
66(66 \%)\end{array}$ & $\begin{array}{l}\text { Intolerance to physical exercise } \\
43(43 \%)\end{array}$ & 16 & 0 \\
\hline $\mathrm{E}$ & 101 & 49 & $1-7$ & $\begin{array}{l}\text { Cough } \\
77(76.2 \%)\end{array}$ & $\begin{array}{l}\text { Poor general conditions } \\
61(60.3 \%)\end{array}$ & $\begin{array}{l}\text { Intolerance to physical exercise } \\
55(54.4 \%)\end{array}$ & 4 & 0 \\
\hline $\mathrm{F}$ & 100 & 47 & $1-5$ & $\begin{array}{l}\text { Cough } \\
50(50 \%)\end{array}$ & $\begin{array}{l}\text { Weight loss } \\
48(48 \%)\end{array}$ & $\begin{array}{l}\text { Poor general conditions } \\
22(22 \%)\end{array}$ & 16 & 3 \\
\hline
\end{tabular}

no dogs scored positive at the Baermann examination in sites $\mathrm{A}, \mathrm{C}$ and $\mathrm{F}$.

The 14 infected dogs showed clinical pictures different one from each other, with the most common reason for inclusion in the study being a combination of signs respiratory in nature along with aspecific signs (Table 2).

All cases but one (case no. 50 at site E) showed respiratory disease, with cough always present with the exception of a dog (case no. 101 at site E) which was referred with tachypnoea and breathing sounds. The clinical visit of case 50 at site E revealed only non-specific signs (Table 2). The majority of the cases showing respiratory distress also showed other cardiopulmonary and general signs, while two dogs (case nos. 101 and 10 at sites B and D, respectively) had respiratory signs alone and one animal (case no. 16 at site E) had only cough and hemorrhagic diarrhoea (Table 2).

In terms of frequency, the most present sign was cough, followed by aspecific signs (Table 3). Other, although less common, respiratory signs were dyspnoea, tachypnoea and

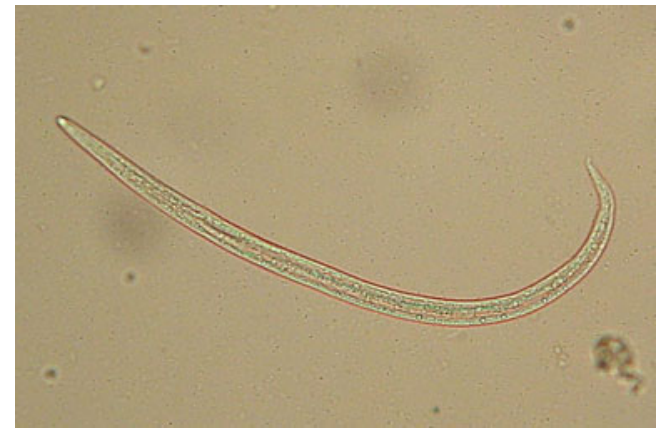

Fig. 1 First stage larva of Angiostrongylus vasorum breathing sounds, while signs of bleeding diathesis were pale mucosae, hemorrhagic diarrhoea and haemorrhage from minor wounds. Other than diarrhoea, the only

Table 2 Dogs infected by Angiostrongylus vasorum in sites B (Lombardy region), D (Lazio region) and $\mathrm{E}$ (Abruzzo region) of Italy and their clinical picture

Dog Site Clinical picture

1 B Weight loss, cough, dyspnoea

101 B Cough, dyspnoea

2 D Intolerance to physical exercise, low performance, poor general condition, cough

10 D Cough

16 E Cough, hemorrhagic diarrhoea

48 E Poor general condition, cough

49 E Poor general condition, lethargy, coagulation disorders ${ }^{\mathrm{a}}$, cough, dyspnoea, shock

50 E Intolerance to physical exercise, low performance, poor general condition, lethargy

74 E Intolerance to physical exercise, low performance, weight loss, poor general condition, cough

78 E Intolerance to physical exercise, low performance, lethargy, breathing sounds, cough

79 E Intolerance to physical exercise, low performance, weight loss, poor general condition, lethargy, cough

82 E Intolerance to physical exercise, low performance, weight loss, poor general condition, breathing sounds, dyspnoea, cough

92 E Intolerance to physical exercise, poor general condition, cough, dyspnoea

101 E Weight loss, lethargy, vomitus, breathing crackles, tachypnoea

${ }^{\text {a }}$ Bleeding from minor wounds, pale mucosae 
Table 3 Percentage of occurrence of clinical signs in 14 dogs (D) infected by Angiostrongylus vasorum in Italy

\begin{tabular}{|c|c|c|}
\hline Signs & $\mathrm{D}$ & Percent \\
\hline Cough & 12 & 85.7 \\
\hline Poor general condition & 8 & 57.1 \\
\hline Intolerance to physical exercise & 7 & 50 \\
\hline Low performance & 6 & 42.9 \\
\hline Lethargy & 5 & 35.7 \\
\hline Weight loss & 5 & 35.7 \\
\hline Dyspnoea & 5 & 35.7 \\
\hline Pulmonary sounds & 2 & 14.3 \\
\hline Vomiting & 1 & 7.1 \\
\hline Lung crackles & 1 & 7.1 \\
\hline Tachypnoea & 1 & 7.1 \\
\hline Coagulation disorders $^{\mathrm{a}}$ & 1 & 7.1 \\
\hline Shock & 1 & 7.1 \\
\hline
\end{tabular}

${ }^{a}$ Bleeding from minor wounds, pale mucosae

gastrointestinal disorder evidenced was vomitus. No neurological signs were detected in any of the infected dogs (Table 3).

\section{Clinical pictures in infected dogs, key examples}

Clinical presentations selected in terms of clinical aspect and interest they have stimulated in the primary care level in veterinarians participating in the study are reported as follows.

Site B, case 1

A 6-year-old Dalmatian female weighing $18 \mathrm{~kg}$, which never moved outside Lombardy region, was referred because of coughing, dyspnoea and weight loss since 1 month of duration. The dog lived outdoor in a garden from an urban area and had history of eating every kind of "potential" food found and never received an anthelmintic treatment in the last years. The dog was thin and dehydrated, and thoracic radiographs showed a mixed interstitial nodular pattern without any evidence of vascular lesions (Fig. 2). Pulmonary ultrasound examination showed several pulmonary nodules (ranging from 2 to $7 \mathrm{~mm}$ of diameters) visualized in both lungs, which were subjected to cytology showing presence of macrophage and inflammatory cells. All these pieces of evidence led to a suspicion of canine hemangiosarcoma. Nonetheless, several larvae of $A$. vasorum were found at Baermann's examination. The dog was treated three times 15 days apart with a spot-on solution containing imidacloprid $10 \%$ /moxidectin $2.5 \%$ (Advocate ${ }^{\circledR}$, Bayer Animal Health) and its health conditions improved quickly. At day 40 from the diagnosis, the faecal examination was negative, respiratory signs were no longer

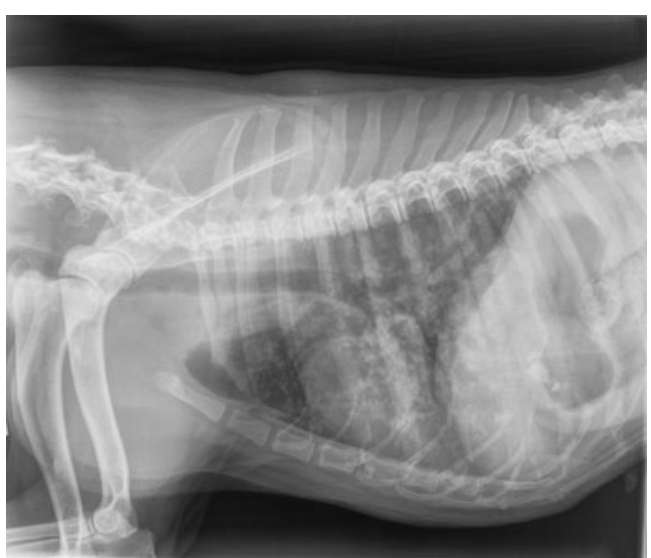

Fig. 2 Thoracic radiograph (latero-lateral view, right recumbency) showing a mixed interstitial nodular pattern without any evidence of vascular lesions (dog 1, site B)

present, thoracic radiographs were greatly improved and no nodular lesions were revealed at lung sonographic examination.

Site B, case 101

A 2-year-old mixed breed was referred for a through clinical evaluation after being scored positive upon a commercial kit detecting Dirofilaria immitis-circulating antigen.

A history of dyspnoea and coughing of mild entity of few weeks of duration was reported, and the physical examination showed no other apparent abnormalities. The animal did not receive recent parasiticides. Thoracic radiographs did not show any abnormality while echocardiography allowed the visualization of few filariid echoes in the right pulmonary artery. No sign of pulmonary hypertension could be detected on B-dimensional and Doppler study, while lung sonography showed the presence of small $(<4 \mathrm{~mm})$ scattered nodular lesions in the pulmonary parenchyma (Fig. 3). Given that the dog scored positive for larvae of $A$. vasorum at the faecal examination, it was treated with a single administration of Advocate ${ }^{\circledR}$. At the re-evaluation 1 month later, coughing completely disappeared and no more nodular lesions were present in the pulmonary parenchyma. Baermann examination was negative, pulmonary sonography showed disappearance of nodular lesions and echocardiography persistence of filariid echoes in the right pulmonary artery without signs of pulmonary hypertension (Fig. 4). Few days later, the dog underwent surgical heartworm removal and recovered completely.

Site E, case 16

An 18-month-old bloodhound hunting male dog living in a mountainous area was referred for clinical evaluation due to recurrent haemorrhagic diarrhoea and coughing. The animal 


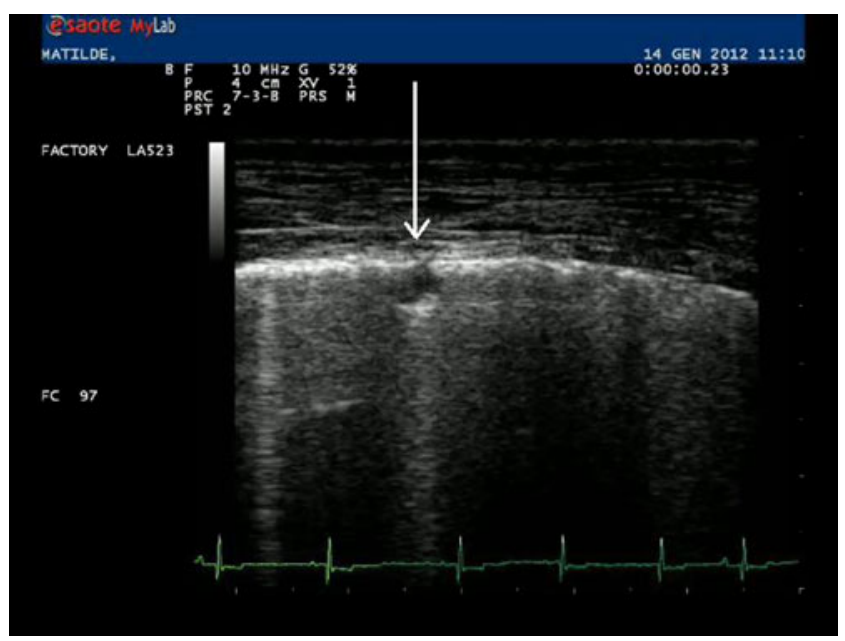

Fig. 3 Lung sonography showing a small nodular lesion (arrow) in the pulmonary parenchyma (dog 101 , site B)

did not show any other cardiac and lung distress or haemostatic abnormality. No further information were available, with the exception of a treatment with a combination of febantel/praziquantel/pyrantel received 2 months before. After the detection of $A$. vasorum larvae, the $\operatorname{dog}$ was treated with a single dose of the aforementioned spot-on formulation and no other episodes of faecal bleeding and coughing were reported to the veterinarian.

\section{Site E, case 78}

A 4-year-old bloodhound hunting male dog living in a rural area was referred with extreme and sudden exercise intolerance, loss of performances, lethargy and persistent coughing. The clinical examination revealed breathing crackles and sounds and $\mathrm{Rx}$ examination showed a diffused bronchial

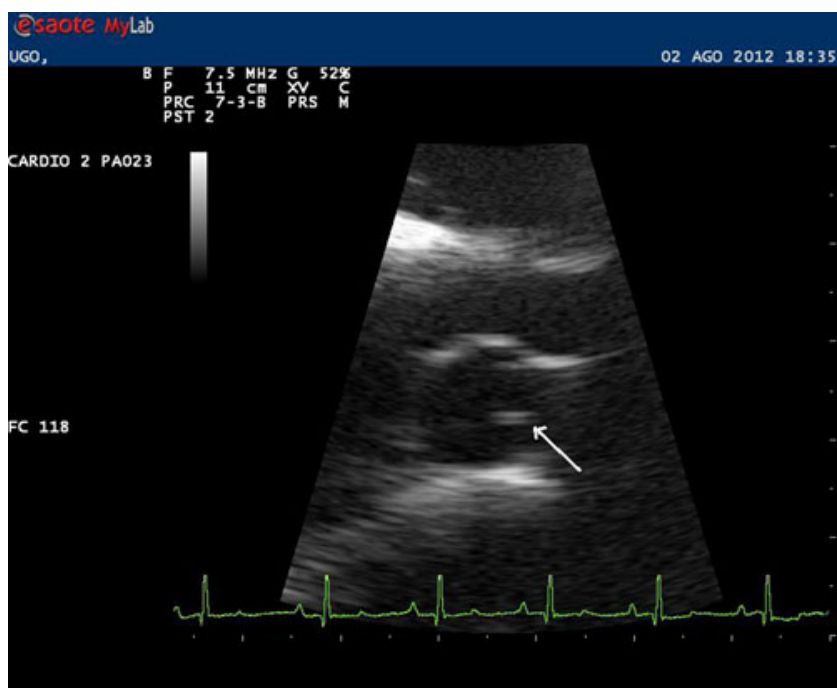

Fig. 4 Echocardiography showing presence of filariid echoes in the right pulmonary artery (arrow) (dog 101, site B) pattern and lung nodular lesions (Fig. 5). The dog had received a combination of febantel/praziquantel/pyrantel and an arthropod repellent 5 months before. The veterinarian made a suspicion of angiostrongylosis, which was confirmed by the detection of larvae at faecal examination. The dog was treated with the moxidectin-containing topical solution and fully recovered with disappearance of signs and pulmonary lesions after few weeks.

\section{Discussion}

The present study represents the first large-scale survey on the presence of $A$. vasorum in naturally infected dogs from Italy and provides new data on the distribution of the parasite in the country. In Italy, angiostrongylosis was firstly found more than 20 years ago in red foxes, while in dogs, it has been described only in the past decade, with an increasing trend in clinical reports (Traversa et al. 2008a, 2010a). Nonetheless, information are still limited to few areas from the centre of the country (Traversa et al. 2010a; Di Cesare et al. 2011) with only single cases or small case series from other regions (Della Santa et al. 2002; Sasanelli et al. 2008; Lepri et al. 2011).

The present study illustrates that canine angiostrongylosis is endemic in Italy and not confined to central regions and suggests a possible geographic expansion, as already hypothesized for other countries (Helm et al. 2010; Morgan and Shaw 2010; Traversa et al. 2010a; Ferdushy and Hasan 2010b).

Given that dogs were recruited on the basis of perception of veterinarians on appropriate signs, the results are not an estimate of absolute parasite prevalence or disease incidence in the selected regions. Cases of asymptomatic angiostrongylosis may occur and the actual presence of $A$. vasorum in symptomatic dogs of this study is likely underestimated because only one Baermann test has been performed for each animal. Indeed, veterinarians were not asked for the necessary three consecutive daily faecal samples (Oliveira-Júnior et al. 2006; Verzberger-Epshtein et al. 2008; Koch and Willesen 2009; Morgan et al. 2010) because this would have likely reduced compliance from the owner and the veterinarians themselves.

The presence of A. vasorum in site B is worthy of note because this is the first report of the nematode from an area hyper-endemic for $D$. immitis. The simultaneous presence of these two cardiopulmonary nematodes can be a diagnostic challenge. Although adult stages of $A$. vasorum have the same location of the better known canine heartworm $D$. immitis, the clinical outcome of the infection can be different (Conboy 2011). On the other hand, overlapping clinical signs (e.g. cough, exercise intolerance) would greatly complicate the diagnostic approaches of clinicians working in 
Fig. 5 Thoracic radiographs (ventro-dorsal views) showing a bronchial pattern and nodular lesions (dog 78, site E)
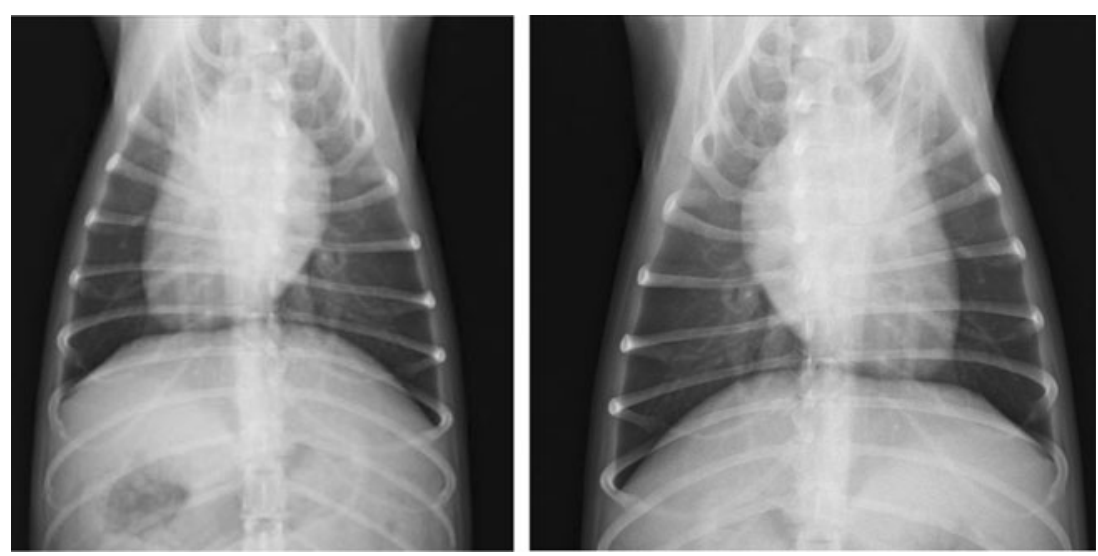

areas where these nematodes live in sympatry. In fact, only echocardiography and lung sonography, along with specific laboratory evidences, may facilitate the diagnosis for similar clinical pictures. Additionally, as shown by case 101 from this site, mixed infection may occur, thus representing both a serious threat for the health of the animal and a challenge for vet practitioners. It is noteworthy that, although $D$. immitis is hyper-endemic along the Po River Valley and northern areas, new autochthonous foci of canine dirofilariosis in southern and central Italy have been recently reported (Otranto et al. 2009; Traversa et al. 2010a, b), including in site $\mathrm{E}$, i.e. the area in which $A$. vasorum is mostly distributed in the country (see below). Vet practitioners throughout Italy can be faced with diagnostic dilemmas posed by both infections, which can either share clinical signs or differ widely.

The high presence of $A$. vasorum in site $\mathrm{E}$ is not surprising because it has been, several times, described from the region in both clinical cases (Traversa et al. 2008a) and epidemiological surveys (Di Cesare et al. 2010, 2011, 2012); thus, the existence of a stable endemic focus in this area of Italy is suggested. The reasons are unclear, but the high presence of the feline mollusk-borne respiratory nematode Aelurostrongylus abstrusus in the same area (Traversa et al. 2008b; Di Cesare et al. 2011) suggests that local ecological drivers may nurture the distribution of gastropods and of pathogens they transmit (Traversa et al. 2010a).

The negativity from site $\mathrm{C}$ does not imply a true absence of the parasite in the region because in this study the infection was diagnosed in two asymptomatic dogs (not shown) from a breeding operation of Caucasian shepherds which was included in the study for the presence of pertinent signs in other dogs in the same kennel. Hence, the possibility that A. vasorum was not detected in some symptomatic dogs cannot be ruled out given the demonstrated presence of the parasite in the same kennel.

While A. vasorum has been reported from site A only anectodically, thus far, the negativity of site $\mathrm{F}$ does not reflect the present distribution of $A$. vasorum. In fact, canine angiostrongylosis has been recently diagnosed in the same region (Sasanelli et al. 2008).

The age of positive animals ranged from 18 months to 9 years. Indeed, dogs of all ages can be infected with $A$. vasorum, even though young subjects, for their playing and alimentary habits, are at more risk especially with severe parasitic burdens for their incomplete immune competency (Martin et al. 1993; Chapman et al. 2004; Day 2007; Koch and Willesen 2009; Helm et al. 2010; Gallagher et al. 2012). The present results differ from published data, i.e. $75 \%$ of animals diagnosed at less than 2.5 years old (Gallagher et al. 2012), because only five infected dogs were $\leq 2.5$ years old. Nonetheless, the information concur with the relatively frequent findings of $A$. vasorum in animals aged between 5 and 12 years (Chapman et al. 2004; Gallagher et al. 2012). Hence, angiostrongylosis should be suspected in all dogs with pertinent clinical signs, regardless of age, but can be excluded in puppies of 2 to 3 months of age for the prepatent period of the worm.

None of the positive animals were treated with a macrocyclic lactone within 12 weeks before sampling. This reflects the tendency to use single doses of a benzimidazole either alone or in combination with other molecules for general parasiticide treatment, rather than treatments treating also A. vasorum infections, as also previously described in other studies (Willesen et al. 2007; Morgan et al. 2010). Therefore, it could be insightful to evaluate the effect of different treatments on the risk of infection and disease in those areas where $A$. vasorum is actually spreading.

Under a clinical standpoint, as expected, clinical signs of infected animals herein examined were consistent with angiostrongylosis. Nonetheless, the vast majority were aspecific and the parasitosis showed a widely varying clinical picture. Veterinarians reported clinical signs similar to those already published elsewhere and considered compatible with angiostrongylosis (Chapman et al. 2004; Koch and Willesen 2009; Helm et al. 2010; Morgan et al. 2010). As previously suggested, severe and complex clinical features published for canine angiostrongylosis are not observations 
selected for publication in the veterinary literature, but are common findings of a multifactorial pathology (Morgan et al. 2010). Such scenario can face veterinarians and parasitologists with relevant challenges under clinical and diagnostic standpoints (Traversa and Guglielmini 2008), despite slight differences in pulmonary damages, e.g. scattered nodular lesions, atypical for canine heartworm disease. Hence, the finding of such lesions in some of infected dogs examined in the present study (Figs. 2 and 4) should be taken into account in the differential in clinical settings, along with aspecific signs like sudden exercise intolerance, like in dog no. 78 at site E.

The case definition in this study was broad, especially because cardiovascular signs included lethargy and exercise intolerance, and general conditions were included as well. This study design was selected on the basis of a previous similar survey carried out in the UK (Morgan et al. 2010) which described the most common presenting signs in infected dogs at primary care level. The pictures described here concur with this previous study, which proved that signs associated with canine angiostrongylosis widely vary, being the most common cardiorespiratory in nature and coagulopathies or neurologic diseases less frequently observed (Chapman et al. 2004; Chapman 2006; Koch and Willesen 2009). Also, it is herein confirmed that vague (e.g. weight loss, lethargy, depression) and gastrointestinal signs may be a finding alone or along with cardiac and/or respiratory evidences (Schelling et al. 1986; Koch and Willesen 2009). The lung compromise found herein (Tables 2 and 3 ) is consistent with previous studies (Martin et al. 1993; Patteson et al. 1993; Chapman et al. 2004; Helm et al. 2010). Auscultation of the lung fields is considered unremarkable unless in rare cases (Chapman et al. 2004) and, accordingly, relevant lung crackles have been herein found in only one dog, which presented a severe clinical picture (Table 2).

In conclusion, $A$. vasorum has an increasing potential range of dispersion in several European areas including Italy (Morgan et al. 2009, 2010; Ferdushy and Hasan $2010 \mathrm{~b}$ ); thus, an increasing population of dogs will be exposed to the infection in the future. There is the necessity of stimulating concern on this infection among vet practitioners, which should always include $A$. vasorum on the list of differential diagnoses when signs are consistent. In fact, angiostrongylosis is a wellestablished parasitic condition in dogs from Italy and other countries and should be considered in dogs from all areas and of all ages even in the presence of a single compatible clinical sign. This is of particular importance because, albeit the parasite has a high clinical impact and may be life-threatening, the anthelmintic treatment is simple, straightforward and most often successful (Willesen et al. 2007; Traversa et al. 2010a).
Acknowledgments The authors are grateful to the following veterinarians who collaborated in the study: Emanuela Di Giulio, Carmelo Flavio Dimitri, Matteo Seghetti, Vincenzo Buono, Stefania Visin, Monica Mandi, Lucia Morosin, Donato Piccolo and Carmelo Furnari. This study was financially supported by Bayer Sanità Animale, Milan, Italy.

Open Access This article is distributed under the terms of the Creative Commons Attribution License which permits any use, distribution, and reproduction in any medium, provided the original author(s) and the source are credited.

\section{References}

Al-Sabi MN, Deplazes P, Webster P, Willesen JL, Davidson RK, Kapel CM (2010) PCR detection of Angiostrongylus vasorum in faecal samples of dogs and foxes. Parasitol Res 107:135-140

Barutzki D, Schaper R (2009) Natural infections of Angiostrongylus vasorum and Crenosoma vulpis in dogs in Germany (2007-2009). Parasitol Res 105:S39-S48

Barutzki D, Schaper R (2011) Results of parasitological examinations of faecal samples from cats and dogs in Germany between 2003 and 2010. Parasitol Res 109(Suppl 1):S45-SS60

Bolt G, Monrad J, Koch J, Jensen AL (1994) Canine angiostrongylosis: a review. Vet Rec 135:447-452

Brennan SF (2008) Canine angiostrongylosis. UK Vet 13:31-35

Chapman PS (2006) Clinical aspects of angiostrongylosis in dogs. Proceedings of the 16th European College of Veterinary Internal Medicine-companion animal proceedings. Amsterdam, the Netherlands

Chapman PS, Boag AK, Guitian J, Boswood A (2004) Angiostrongylus vasorum infection in 23 dogs (1999-2002). J Small Anim Pract 45:435-440

Conboy GA (2011) Canine angiostrongylosis: the French heartworm: an emerging threat in North America. Vet Parasitol 176:382-389

Day MJ (2007) Immune system development in the dog and cat. J Comp Pathol 137:10-15

Della Santa D, Citi S, Marchetti V, Tardoni S (2002) Infestione da Angiostrongylus vasorum nel cane: review della letteratura e presentazione di un caso clinico. Veterinaria 9-14 (In Italian)

Denk D, Matiasek K, Just FT, Hermanns W, Baiker K, Herbach N, Steinberg T (2009) Disseminated angiostrongylosis with fatal cerebral haemorrhages in two dogs in Germany: a clinical case study. Vet Parasitol 160:100-108

Di Cesare A, Meloni S, Milillo P, Castagna G, Otranto D, Paoletti B, Bartolini R, Avolio S, Traversa D (2010) Feline and canine cardio-pulmonary nematodes in central and southern Italy. Proceedings of the XXVI SoIPa Congress. June 22 to 25, Perugia, Italy, p 307

Di Cesare A, Castagna G, Meloni S, Milillo P, Latrofa S, Otranto D, Traversa D (2011) Canine and feline infections by cardiopulmonary nematodes in central and southern Italy. Parasitol Res 109: S87-S96

Di Cesare A, Castagna, Meloni S, Milillo P, Otranto D, Pampurini F, Schaper R, Petrucci L, Traversa D (2012) Occurrence of feline and canine lungworms in central and southern Italy in 2009-2011. Proceedings of the XXVII SoIPa Congress. June 26 to 29, Alghero, Italy, p 278

Dias SR, Dos Santos Lima W (2012) Effect of temperature on activity of third-stage larvae of Angiostrongylus vasorum. Parasitol Res 110:1327-1330

Ferdushy T, Hasan MT (2010a) Survival of first stage larvae (L1) of Angiostrongylus vasorum under various conditions of temperature and humidity. Parasitol Res 107:1323-1327 
Ferdushy T, Hasan MT (2010b) Angiostrongylus vasorum: the 'French Heartworm'. Parasitol Res 107:765-771

Gallagher B, Brennan SF, Zarelli M, Mooney CT (2012) Geographical, clinical, clinicopathological and radiographic features of canine angiostrongylosis in Irish dogs: a retrospective study. Ir Vet J 65:5

Garosi LS, Platt SR, McConnell JF, Wray JD, Smith K (2005) Intracranial haemorrhage associated with Angiostrongylus vasorum infection in three dogs. J Small Anim Pract 46:93-99

Gredal H, Willesen JL, Jensen HE, Nielsen OL, Kristensen AT, Koch J, Kirk RK, Pors SE, Skerritt GC, Berendt M (2011) Acute neurological signs as the predominant clinical manifestation in four dogs with Angiostrongylus vasorum infections in Denmark. Acta Vet Scand 53:43

Helm JR, Morgan ER, Jackson MW, Wotton P, Bell R (2010) Canine angiostrongylosis: an emerging disease in Europe. J Vet Emerg Crit Care (San Antonio) 20:98-109

Jefferies R, Morgan ER, Helm J, Robinson M, Shaw SE (2011) Improved detection of canine Angiostrongylus vasorum infection using realtime PCR and indirect ELISA. Parasitol Res 109:1577-1583

Koch J, Willesen JL (2009) Canine pulmonary angiostrongylosis: an update. Vet J 179:348-359

Lepri E, Veronesi F, Traversa D, Conti MB, Marchesi MC, Miglio A, Mandara MT (2011) Disseminated angiostrongylosis in a dog from Italy: pathological and parasitological findings. Parasitol Res 109:505-508

Levine ND (1980) Nematode parasites of domestic animals and man, 2nd edn. Burgess, Minneapolis, 477

Martin MWS, Ashton G, Simpson VR, Neal C (1993) Angiostrongylosis in Cornwall: clinical presentations of eight cases. J Small Anim Pract 34:20-25

McGarry JW, Morgan ER (2009) Identification of first-stage larvae of metastrongyles from dogs. Vet Rec 165:258-261

Morgan E, Shaw S (2010) Angiostrongylus vasorum infection in dogs: continuing spread and developments in diagnosis and treatment. J Small Anim Pract 51:616-621

Morgan ER, Jefferies R, Krajewski M, Ward P, Shaw SE (2009) Pulmonary angiostrongylosis: the influence of climate on parasite distribution. Parasitol Int 58:406-410

Morgan ER, Jefferies R, van Otterdijk L, McEniry RB, Allen F, Bakewell M, Shaw SE (2010) Angiostrongylus vasorum infection in dogs: presentation and risk factors. Vet Parasitol 173:255-261

Oliveira-Júnior SD, Barçante JMP, Barcante TA, Dias SRC, Lima WS (2006) Larval output of infected and re-infected dogs with Angiostrongylus vasorum. Vet Parasitol 141:101-106

Otranto D, Capelli G, Genchi C (2009) Changing distribution patterns of canine vector borne diseases in Italy: leishmaniosis vs. dirofilariosis. Parasit Vectors 2:S2

Papazahariadou M, Founta A, Papadopoulos E, Chliounakis S, Antoniadou-Sotiriadou K, Theodorides Y (2007) Gastrointestinal parasites of shepherd and hunting dogs in the Serres Prefecture, Northern Greece. Vet Parasitol 148:170-173
Patteson MW, Gibbs C, Wotton PR, Day MJ (1993) Angiostrongylus vasorum infection in seven dogs. Vet Rec 133:565-570

Perry AW, Hertling R, Kennedy MJ (1991) Angiostrongylosis with disseminated larval infection associated with signs of ocular and nervous disease in an imported dog. Can Vet J 32:430431

Prestwood AK, Greene CE, Mahaffey E, Burgess DE (1981) Experimental canine angiostrongylosis: I. Pathologic manifestations. J Am Anim Hosp Assoc 17:491-497

Sasanelli M, Paradies P, Otranto D, Lia RP, Capraris D (2008) Haemothorax associated with Angiostrongylus vasorum infection in a dog. J Small Anim Pract 49:417-420

Schelling CC, Greene CE, Prestwood AK, Tsang VCW (1986) Coagulation abnormalities associated with acute Angiostrongylus vasorum infection in dogs. Am J Vet Res 47:2669-2673

Traversa D, Guglielmini C (2008) Feline aelurostrongylosis and canine angiostrongylosis: a challenging diagnosis for two emerging verminous pneumonia infections. Vet Parasitol 157:163-174

Traversa D, Torbidone A, Malatesta D, Guglielmini C (2008a) Occurrence of fatal canine Angiostrongylus vasorum infection in Italy. Vet Parasitol 152:162-166

Traversa D, Lia RP, Iorio R, Boari A, Paradies P, Capelli G, Avolio S, Otranto D (2008b) Diagnosis and risk factors of Aelurostrongylus abstrusus (Nematoda, Strongylida) infection in cats from Italy. Vet Parasitol 153:182-186

Traversa D, Di Cesare A, Conboy G (2010a) Canine and feline cardiopulmonary parasitic nematodes in Europe: emerging and underestimated. Parasit Vectors 3:62

Traversa D, Aste G, Milillo P, Capelli G, Pampurini F, Tunesi C, Santori D, Paoletti B, Boari A (2010b) Autochthonous foci of canine and feline infections by Dirofilaria immitis and Dirofilaria repens in central Italy. Vet Parasitol 169:128-132

van Doorn DC, van de Sande AH, Nijsse ER, Eysker M, Ploeger HW (2009) Autochthonous Angiostrongylus vasorum infection in dogs in The Netherlands. Vet Parasitol 162:163-166

Verzberger-Epshtein I, Markham RJF, Sheppard JA, Stryhn H, Whitney H, Conboy GA (2008) Serologic detection of Angiostrongylus vasorum infection in dogs. Vet Parasitol 151:53-60

Wessmann A, Lu D, Lamb CR, Smyth B, Mantis P, Chandler K, Boag A, Cherubini GB, Cappello R (2006) Brain and spinal cord haemorrhages associated with Angiostrongylus vasorum infection in four dogs. Vet Rec 158:858-863

Whitley NT, Corzo-Menendez N, Carmichael NG, McGarry JW (2005) Cerebral and conjuntival haemorrhages associated with von Willebrand factor deficiency and canine angiostrongylosis. J Small Anim Pract 46:75-78

Willesen JL, Kristensen AT, Jensen AL, Heine J, Koch J (2007) Efficacy and safety of imidacloprid/moxidectin spot-on solution and fenbendazole in the treatment of dogs naturally infected with Angiostrongylus vasorum (Baillet, 1866). Vet Parasitol 147:258264 